\title{
sciendo
}

\section{On building early-warning systems for preventing the deterioration of financial institutions' performance}

\author{
Adrian COSTEA \\ Bucharest University of Economic Studies, Bucharest, Romania \\ adrian.costea@csie.ase.ro
}

\begin{abstract}
This paper assesses the financial performance of Romania's non-banking financial institutions (NFIs) using a neural network training algorithm proposed by Kohonen, namely the Self-Organizing Maps algorithm. The algorithm takes the financial dataset and positiones each observation into a selforganizing map (a two-dimensional map) which can be latter used to visualize the trajectories of an individual NFI and explain it based on different performance dimensions, such as capital adequacy, assets' quality and profitability. Further, we use the map as an early-warning system that would accurately forecast the NFIs future performance (whether they would stay or be eliminated from the NFI's Special Register three quarters into the future). The results are promising: the model is able to correctly predict NFIs' performance movements. Finally, we compared the results of our SOM-based model with those obtained by applying a multivariate logit-based model. The SOM model performed worse in discriminating the NFIs' performance: the performance classes were not clearly defined and the model lacked the interpretability of the results. In the contrary, the multivariate logit coefficients have nice interpretability and an individual default probability estimate is obtained for each new observation. However, we can benefit from the results of both techniques: the visualization capabilities of the SOM model and the interpretability of multivariate logit-based model.
\end{abstract}

Keywords: early-warning systems, non-banking financial institutions, self-organising maps, performance evaluation, financial ratios

\section{Introduction}

The problem of accurately assess the performance of financial institutions and especially that of non-banking financial institutions (NFI) is very important for the central bank which is the institution in charge with monitoring and prudentially supervising these entities. In Romania, there are around 200 NFIs which need to be monitored and, out of these, 60 included in a Special Register which need to be also prudentially supervised, because they are more important in terms of loans granted and the level of capital they own. In order to monitor these entities the central bank has at its disposal limited amount of resources of time and personel. Therefore, for the central bank it is crucial to find models that would reveal NFIs which need to be more carefully looked at and models that would predict the deterioration of NFIs' performance three, six or nine months before it actually happens.

This paper assesses the financial performance of Romania's non-banking financial institutions (NFIs) using a neural network training algorithm proposed by Kohonen, namely the Self-Organizing Maps algorithm. The algorithm takes the financial dataset and positiones each observation into a self-organizing map (a two-dimensional map) which can be latter used to visualize the trajectories of an individual NFI and explain it based on different performance dimensions, such as capital adequacy, assets' quality and profitability. Moreover, we go one step further and use the map created to build an early-warning system 
for NFIs' performance deterioration (performance deterioration is encountered when the NFI is eliminated from the Special Register that includes NFIs based on certain performance criteria).

\section{Literature review}

Kohonen (1997) proposed the Self-Organising Maps (SOM) clustering algorithm which has been used extensively in financial applications. Costea \& Eklund (2003) used clustering analysis in terms of self-organizing maps to find possible clusters in data in terms of financial performance and, then, build classifiers using two different predictive models (multinomial logistic regression and decision trees) and compare the results of these models. Their findings claim that the results of the two classification techniques are similar in terms of accuracy rates and class predictions. Costea (2006) constructs a framework using Data Mining techniques that enables the author to make class predictions about telecommunication companies' financial performance. The proposed methodology allows the author to analyze the movements of the largest telecommunications companies, to see how companies perform financially compared to their competitors, what they are good at, who are the major competitors in this industry, etc. Costea \& Bleotu (2012) proposed a modified version of the Fuzzy C-Means clustering algorithm to classify the non-banking financial institutions as to their financial performance. The results show that the pattern allocation has been improved with the application of the new proposed algorithm.

Borio \& Lowe (2002) developed a very simple early-warning system for banking crises: they relied on three main indicators (credit, asset prices and real exchange rate), setup some thresholds for these indicators and, if these thresholds were crossed cumulatively then this would be a signal that a crisis might occur. All variables are measured as gaps, ie as a percentage point or percentage deviation from an ex ante, recursively calculated HodrickPrescott trend (Borio \& Lowe, 2002, p. 49). The authors obtained good crisis' prediction rates (up to 60\%) with the best results intuitively obtained for the highest time-horizon case (3years).

Bussière \& Fratzscher (2002) developed an early-warning system model for predicting financial crises by applying a multinomial logit model (instead the classical twocase output variable, the authors used a three-case output variable by adding the "post-crisis period" as a new value for the dependent variable). The results show that the model would have correctly predicted a large majority of crises in emerging markets. The dataset consisted of about 32 open emerging market economies for the period 1993-2001. Also, the paper provides some hints about the optimal design of the EWS models for policy-makers.

Candelon et al. (2009) propose a statistical framework for evaluating EWS models for currency crises. The EWS models' evaluating criteria include ROC curves, Kuiper Score, Petra Index and Bayesian Error Rate. Also, the authors propose a method of finding the optimal cut-off rate (the value that signals the crisis) by maximizing simultaneously and conditionaly two model accuracy-based measures: sensitivity and specificity. The data covers 12 countries with monthly frequency, spans from January 1985 to January 2005 and is extracted via Datastream. Based on the above-mentioned criteria, the authors compare two EWS models: panel logit and a Markov switching model, the former outperforming the later.

Davis \& Karim (2008) compare two EWS models: the logit and signal extraction EWS and suggest that logit is the most appropriate approach for global EWS, while signal extraction is better for country specific EWS. At the same time, the authors sugest that the 
policy maker's objectives play an important role in designing the predictive systems and setting-up the related thresholds. The results show that the GDP growth and terms of trade are robust leading indicators for banking crisis. The authors argue that the definition of the output variable (that defines the banking crisis) is essential in designing an effective EWS model.

Kaminsky \& Reinhart (1999) propose a set of 15 macroeoconomic variables as predictors (early warning indicators - EWIs) of banking crisis. The data was collected for a number 20 countries that experienced banking crises during 1970-1995 period. The criterion used by the authors to construct and rank alternative signals is the so-called noiseto-signal ratio (NSR). Demirgüç-Kunt \& Detragiache (1999) explore the use of multivariate logit model of banking crisis probabilities for monitoring the banking sector fragility. They propose as a crisis signaling criterion the "loss function of the decision maker" (DemirgüçKunt \& Detragiache, 1999, p.12) which takes into account three aspects: the probability of type I and type II errors associated with the threshold, the unconditional probability of a banking crisis and the cost to the decision maker of taking preventive action relative to the cost of an unanticipated banking crisis.

Drehmann \& Juselius (2013) use the receiver operating characteristic (ROC) curve to evaluate EWIs for banking crises. In particular, the area under the curve (AUC) is used due to its nice interpretability. Also, another advantage of using ROC curves is that, in the literature (e.g. Janes et al., 2009 and Pepe et al., 2009, cited in Drehmann \& Juselius, 2013, p. 3), there are available estimators (parametric and non-parametric), confidence bands and Wald statistics for comparing the AUCs of two signals. The results show that the credit-to-GDP gap was the best indicator in the case of longer horizons, while a new indicator, the debt service ratio (DSR), consistently outperform other measures in the case of shorter ones.

Hardy \& Pazarbașioğlu (1998) found that while the main macroeconomic indicators were of limited value in predicting the Asian crises, the best warning signals were given by proxies for the vulnerability of the banking and corporate sectors. The data sample consist of 50 countries, 38 of which suffered a total of 43 episodes of banking system crisis or significant problems. Four episodes were used for out-of-sample testing. The explanatory variables were divided in real sector, banking sector and other potential shocks variables. The empirical findings suggest that a consumption boom in the years preceding a crisis can be a leading indicator and, also, that the occurences of the crises are associated with a sharp decrease of the real effective exchange rate (Hardy \& Pazarbașioğlu, 1998, p. 20).

All the above papers related with the development of performance benchmarking and EWS models were focused on credit institutions (banks). Consequently, we identified potential contributions that could be brought to the research field of assessing comparatively the performance of different entities, such as:

- the application of the algorithms proposed in previous research (Costea, 2005) and other Data Mining methods for elaborating classification/EWS models for NFIs' performance deterioration;

- the utilization of clustering as an EWS model;

- the utilization of visualization techniques for analyzing the evolution of NFIs over time;

- the application of clustering techniques for discovering abnormal situations of NFIs.

In this paper we address all the issues mentioned above by applying the results of what we obtained when we applied Self-Organising Map algorithm to the same NFIs' performance dataset in our previous work (Costea, 2013). 
The degree of originality/innovation of proposed research methods and objectives of our paper is made clear from the literature. The application of the SOM algorithm in the classification of financial institutions as to their economic performance is a relatively new area of research. In the next Section we present shortly a NFIs' performance assessment model proposed in one of our previous studies (Costea, 2013) which is applied here in the case of the three worst performing NFIs.

\section{Applying the SOM model}

In a previous paper (Costea, 2013) we assessed comparatively the performance of NFIs which are included in the Special Register. We concentrated on NFIs that have as main activity financial leasing and are active: they have been included in the central bank registers since the introduction of the regulatory framework for these institutions in Romania. The dataset used in Costea (2013) consists of three financial indicators: Equity ratio (Leverage) for the "capital adequacy" dimension, Loans granted to clients (net value) / total assets (net value) for the "assets' quality" dimension and Return on assets (ROA) for the "profitability" dimension. The data collected annually for four years (2007-2010) and for 11 NFIs, totalled 44 observations. After we have applied (see Costea, 2013) the Self-Organising Map (SOM) algorithm developed by Kohonen in early 80's (Kohonen, 1997) we have obtained the final 6x4 map which we show in Figure 1. The map contains 24 "raw" clusters (any of the 24 hexagons in the map). After the training, each neuron contains a number of observations or none.

After we have obtained the map with the 24 "raw" clusters, we grouped them to form "real" clusters. This was done by using the U-matrix method (looking at the borders between "raw" clusters), by analysing the feature plane for each input variable and the observations that belong to each cluster. In this way we have identified 4 "real" clusters (clusters A, B, C, and D in Figure 1).

We can use the descriptive SOM model obtained in Costea (2013) in order to accommodate new companies on the map as data became available. This is done by calculating the euclidean distances of each new raw data, after preprocessing, to the previously obtained clusters' centers and assigning the observations to the closest cluster (the cluster for which we obtain the smallest distance from the observation to its center). Furthermore, we can calculate a probability of default for each performance cluster by simply dividing the number of default NFIs in the cluster to the total number of observations within the cluster, thus simulating an early-warning system. We considered quarterly data between Q1 2007 and Q4 2012 for around 68 NFIs registered in the Special register kept at National bank of Romania obtaining approximately 1140 data points. The Special register includes only those NFIs from the General register which meet certain criteria of performance in terms of loans and borrowings. NFIs which meet these criteria corresponding to three reportingperiods in a row or three quarters are entered in the Special register. Conversely, if a NFI from the Special register does not match the criteria for three consecutive quarters, it will be de-classified in the General register. 


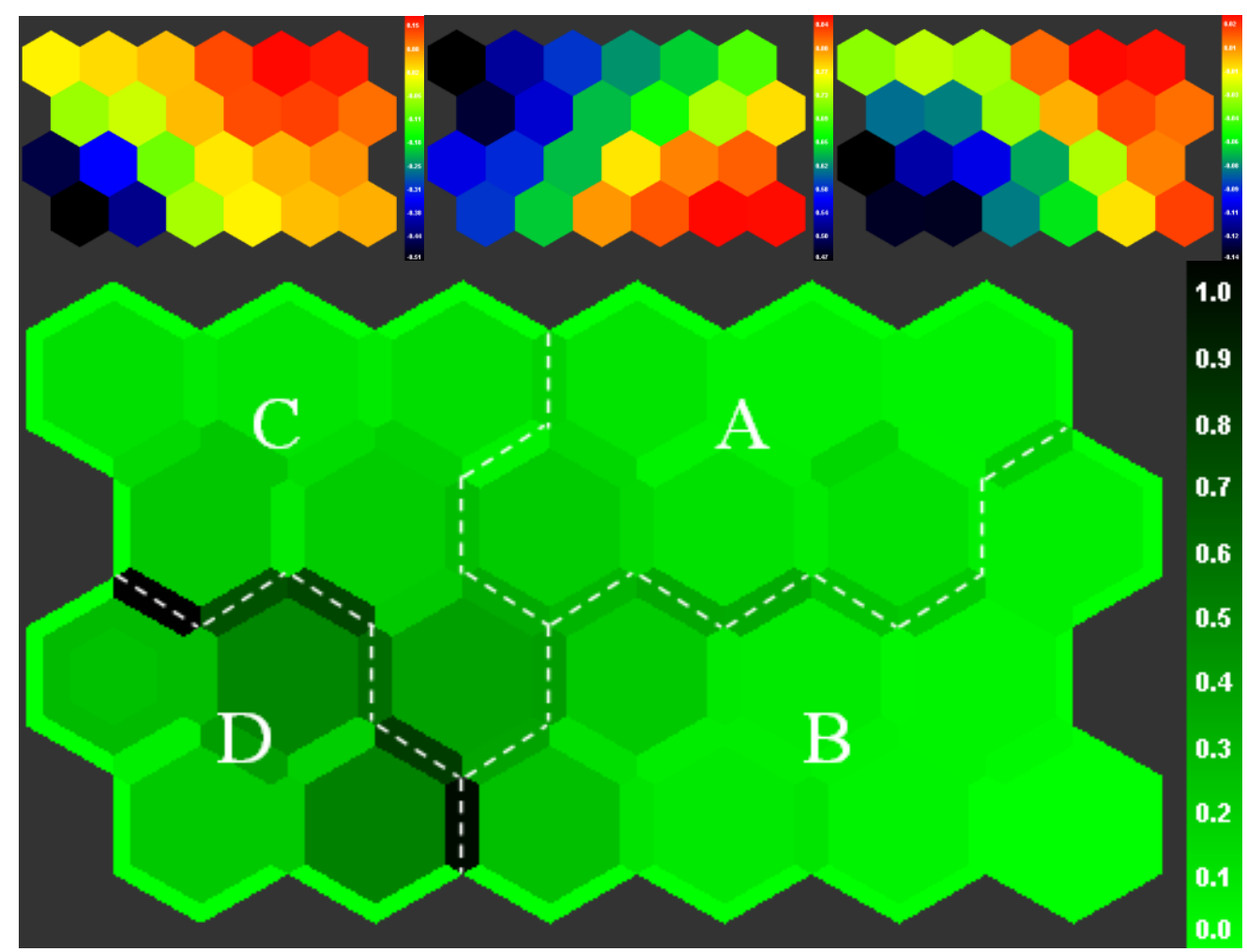

Figure 1. The SOM based on NFIs performance dataset: 24 "raw" clusters and 4 identified "real" clusters. On the top of the figure we display the component planes for the 3 variables: Leverage, Loans/Asstes and ROA

Source: adapted from Costea (2013)

Therefore, we considered that a NFI "defaulted" in the current quarter if it was removed from the Special register three quarters later. Consequently, we had to discard a number of data points from the initial dataset: if one NFI "defaulted" in the current quarter, we discarded the data point associated with that NFI in the subsequent quarters until the removal from the Special register. We ended up with 1111 available observations (Q1 2007 : Q4 2012). We further divided these 1111 observations in two: the data between Q1 2007 and Q1 2012, in total 958 observations, were used to recalculate the clusters' centers of the SOM model proposed in Section 2. Out of these 958 observations 18 were "defaults". The data from the last three quarters (Q2 : Q4 2012) were used to run the forecasts on Q1 2013 : Q3 2013. In this way we can signal early (three quarters earlier) any performance deterioration or improvement.

The distribution of the 958 observations to the 4 "real" clusters obtained in Section 2 is presented in the Table 1.

As it is shown in Table 1, we can calculate now the probabilities of default for each cluster and label them in the increasing order of default risk. Moreover, we can calculate new centers for the four clusters based on the allocation of the 958 observations (see Table 2). 
Table 1. The structure of the SOM model clusters after allocation

\begin{tabular}{|c|c|c|c|c|c|c|c|}
\hline $\begin{array}{c}\text { \# of obs. } \\
\text { before } \\
\text { allocation }\end{array}$ & Leverage & $\begin{array}{c}\text { Earning } \\
\text { power }\end{array}$ & ROA & $\begin{array}{c}\text { \# of obs. } \\
\text { after } \\
\text { allocation }\end{array}$ & $\begin{array}{c}\text { \# of } \\
\text { defaults }\end{array}$ & $\begin{array}{c}\text { Probability } \\
\text { of default } \\
\text { (\%) }\end{array}$ & $\begin{array}{c}\text { Performance } \\
\text { Class (in } \\
\text { increasing } \\
\text { order of risk) }\end{array}$ \\
\hline 8 & 0.1477 & 0.6348 & 0.0082 & 116 & 1 & 0.86 & A \\
\hline 22 & 0.0298 & 0.8113 & -0.0224 & 773 & 12 & 1.55 & B \\
\hline 9 & 0.0139 & 0.5323 & -0.0250 & 56 & 4 & 7.14 & C \\
\hline 5 & -0.5215 & 0.5733 & -0.1324 & 13 & 1 & 7.69 & D \\
\hline
\end{tabular}

However, this approach would not have the same result (in terms of the distribution of the observations within the clusters) as that obtained if we would have applied the SOM algorithm and the procedure described in Section 2 directly to all 958 observations. The problem with retraining a SOM model is that the algorithm is heavily parameterized and choosing the right setting can sometimes be very challenging. Moreover, generally, more data implies more noise within data which leads to some critical choices related to the SOM algorithm: the preprocessing method, the way the outliers and abnormal values are handled. 0 more stable approach to building classification/EWS models so as to accommodate newly available data and to make accurate predictions related to the performance class for these data would be to invoke a classification algorithm instead of using the prescriptive capabilities of a clustering one (e.g. SOM clustering algorithm) which it is done in Moinescu \& Costea (2014). The authors propose a logistic regression-based EWS for classifying the NFIs based on their financial performance. A comparative analysis between the current results and those from Moinescu \& Costea (2014) is provided in a separate section.

Table 2. The new clusters' centers after the allocation of the 958 observations

\begin{tabular}{|c|c|c|c|c|}
\hline $\begin{array}{c}\text { \# of obs. after } \\
\text { allocation }\end{array}$ & Leverage & $\begin{array}{c}\text { Earning } \\
\text { power }\end{array}$ & ROA & $\begin{array}{c}\text { Performance Class } \\
\text { (in increasing order of risk) }\end{array}$ \\
\hline 116 & 0.3273 & 0.6086 & 0.00723 & A \\
\hline 773 & 0.0571 & 0.9692 & -0.0130 & B \\
\hline 56 & 0.0721 & 0.2990 & -0.0076 & C \\
\hline 13 & -1.7056 & 2.5638 & -1.4399 & D \\
\hline
\end{tabular}

Source: Authors' own research

In Table 3 we used the data for the last three quarters in 2012 (153 observations, 51 for each quarter) and show what are the results of applying our EWS model to predict the performance class in the first three quarters for 2013 (whether the observation is classified under the performance class A, B, C or D).

Table 3. Allocation of NFIs into performance classes using the SOM model

\begin{tabular}{|c|c|c|c|c|c|c|}
\hline $\begin{array}{c}\text { Performance Class (in } \\
\text { increasing order of risk) }\end{array}$ & Q1 2013 & $\begin{array}{c}\text { Q1 2013 } \\
(\%)\end{array}$ & Q2 2013 & $\begin{array}{c}\text { Q2 2013 } \\
(\%)\end{array}$ & Q3 2013 & $\begin{array}{c}\text { Q3 2013 } \\
(\%)\end{array}$ \\
\hline A & 9 & 18 & 9 & 18 & 8 & 16 \\
\hline B & 39 & 76 & 39 & 76 & 40 & 78 \\
\hline C & 1 & 2 & 2 & 4 & 2 & 4 \\
\hline D & 2 & 4 & 1 & 2 & 1 & 2 \\
\hline Total & 51 & 100 & 51 & 100 & 51 & 100 \\
\hline
\end{tabular}

Source: Authors' own research 
According to the SOM model the majority of the NFIs are classified in the B performance class which is a medium risk performance class. However, this class has a rather low probability of default ( $1.55 \%$, see Table 2 ) which signals a low risk of default. The results show a moderate deterioration of NFIs' performance in the first three quarters of 2013 . This corresponds to the reality since, during 2013, there were only 3 NFIs' defaults.

\section{Comparative analysis with previously reported results}

In Moinescu \& Costea (2014), the authors proposed an early warning system for the NFIs' defaults based on a multinomial logistic regression approach. If we compare the results of our SOM-based EWS model with those reported using the logit-based model (see Table 4) we can say that the SOM model performs worse in discriminating the NFIs' performance, since, in this case, the performance classes are not clearly defined: it is difficult to make a hierarchy between class A and class B since, as we have stated in Section 2, the companies in class A are the only ones that in average have positive profitability, while the companies in class B have in average the highest values for the assets' quality dimension. However, in both cases, if we take into account that the first two classes form a low risk super-class and the last two a highrisk one, the results are similar: in both cases around $90 \%$ of the cases are concentrated in the first super-class, while the rest remain in the second one, for all three quarters.

Table 4: Allocation of NFIs into performance classes using the multinomial logistic regression (MLR-) and SOM-based models

\begin{tabular}{|c|c|c|c|c|c|c|}
\hline \multirow{2}{*}{$\begin{array}{c}\text { Performance Class } \\
\text { (in increasing } \\
\text { order of risk) }\end{array}$} & \multicolumn{2}{|c|}{ Q1 2013 (\%) } & \multicolumn{2}{c|}{ Q2 2013 (\%) } & \multicolumn{2}{c|}{ Q3 2013 (\%) } \\
\cline { 2 - 7 } & MLR & SOM & MLR & SOM & MLR & SOM \\
\hline A & 18 & 18 & 27 & 18 & 18 & 16 \\
\hline B & 75 & 76 & 65 & 76 & 64 & 78 \\
\hline C & 6 & 2 & 4 & 4 & 10 & 4 \\
\hline D & 2 & 4 & 4 & 2 & 8 & 2 \\
\hline Total & 51 & 100 & 51 & 100 & 51 & 100 \\
\hline
\end{tabular}

Source: Authors' own research

Another drawback in using the SOM model as a performance forecasting mechanism is the lack of interpretability of how the model has yield a certain class performance for a (new) observation. In this respect the logistic regression model is richer in information since it provides an individual default probability for each new observation and, at the same time, we can use the logistic regression coefficients to interpret how this probability has been obtained. However, our performance classification experiments clearly show the advantages of using both techniques at the same time (the vizualization capabilities of SOM model and the interpretability of logistic regression results).

\section{Conclusions}

In this paper we applied an artificial intelligence model (based on Self-Organising Maps SOM - algorithm, an unsupervised neural network training algorithm) to assess comparatively the performance of Romania's non-banking financial institutions (NFIs). The SOM results show four performance classes and we were able to estimate the probabilities of default for each class. The dataset consisted of quarterly data for 68 NFIs between 2007 and 2012 and different NFIs' performance indicators (calculated in order to measure three 
most important performance dimensions: capital adequacy, assets' quality and profitability). We used the SOM model to estimate the allocation into performance classes for the NFIs in the first three quarters in 2013. The SOM model accurately classified the NFIs showing a moderate deterioration (which corresponded to reality) of these entities.

We compared the results of our SOM-based model with those obtained by applying a multivariate logit-based model proposed in Moinescu \& Costea (2014). The SOM model performed worse in discriminating the NFIs' performance: the performance classes were not clearly defined and the model lacked the interpretability of the results. In the contrary, the multivariate logit coefficients have nice interpretability and an individual default probability estimate is obtained for each new observation. However, we can benefit from the results of both techniques: the visualization capabilities of the SOM model and the interpretability of multivariate logit-based EWS model.

\section{References}

Borio, C., \& Lowe, P. (2002). Assessing the risk of banking crises. BIS Quarterly Review, No. December, 43-54.

Bussière, M., \& Fratzscher, M. (2002). Towards a newly warning system of financial crisis. European Central Bank Working Paper Series, Working Paper No. 145.

Candelon, B., Dumitrescu, E., \& Hurlin, C. (2009). How to evaluate an early-warning system: Toward a unified statistical framework for assessing financial crises forecasting methods. Maastricht University $(R M / 10 / 046)$.

Cerna, S., Donath, L., Seulean, V., Herbei, M., Bărglăzan, D., Albulescu, C., \& Boldea, B. (2008). Financial Stability. Timişoara: West University Publishing House.

Costea, A. (2005). Computational Intelligence Methods for Quantitative Data Mining. TUCS PhD dissertation No. 67, Åbo Akademi University, Turku, Finland.

Costea, A. (2006). The Analysis of the Telecommunications Sector by the Means of Data Mining Techniques. Journal of Applied Quantitative Methods (JAQM), 1(2), 144-150.

Costea, A. (2013). Performance benchmarking of non-banking financial institutions by means of Self-Organising Map algorithm. East-West Journal of Economics and Business, XVI(1), 37-58.

Costea, A., \& Bleotu, V. (2012). A new fuzzy clustering algorithm for evaluating the performance of non-banking financial institutions in Romania. Economic Computation and Economic Cybernetics Studies and Research, 46(4), 179-199.

Costea, A., \& Eklund, T. (2003). A Two-Level Approach to Making Class Predictions. In RH. Sprague Jr. (ed.), Proceedings of $36^{\text {th }}$ Annual Hawaii International Conference on System Sciences (HICSS 2003) (9 pages). IEEE Computer Society, Hawaii, USA, January 6-9, 2003, Track: Decision Technologies for Management, Minitrack: Intelligent Systems and Soft Computing, ISBN: 0-7695-1874-5.

Davis, E.P., \& Karim, D. (2008). Comparing Early Warning Systems for Banking Crises. Journal of Financial Stabilitv, 4(2), 89-120.

Demirgüc-Kunt, A., \& Detragiache, E. (1999). Monitoring banking sector fragilitv: A multivariate approach with an application to the 1996-97 crisis. Working Paper of the International Monetary Fund, No. 147.

Drehmann, M., \& Iuselius, M. (2013). Evaluating early warning indicators of banking crises: Satisfying policy requirements. BIS Working Papers, No. 421.

Hardy, D.C., \& Pazarbașioğlu, C. (1998). Leading Indicators of Banking Crises: Was Asia different? Working Paper of the International Monetary Fund, No. 91.

Janes, H., Longton, G., \& Pepe, M. (2009). Accommodating covariates in ROC analysis. Stata Journal, 9.

Kaminsky, G.L., \& Reinhart, C.M. (1999). The twin crises: the causes of banking and balanceof-payments problems. American Economic Review, 89(3), 473-500. 
Kohonen, T. (1997). Self-Organising Maps (2 $2^{\text {nd }}$ ed.). Heidelberg: Springer-Verlag.

Kohonen, T., Hynninen, J., Kangas, J., \& Laaksonen, J. (1996). SOM_PAK: The Self-Organising Map Program Package. Helsinki University of Technology, Report A31, Otaniemi.

Moinescu, B., \& Costea, A. (2014). Towards an early-warning system of distressed nonbanking financial institutions. Economic Computation and Economic Cybernetics Studies and Research, 48(2), 75-90.

Pepe, M., Janes, H., \& Longton, G. (2009). Estimation and comparison of receiver operating characteristic curves. Stata Journal, 9. 